\title{
Análise Clínica, Urodinâmica e Ultra-Sonográfica de Mulheres Continentes e Com Incontinência Urinária de Esforço, Consoante o Tempo de Pós-Menopausa
}

Tese de Mestrado apresentada à Universidade Federal de São Paulo Escola Paulista de Medicina em 04/07/97

Autor: Vânia Maria Borges Wakavaiachi

Orientador: Prof. Dr. Manoel João Batista Castello Girão

Estudaram-se 57 pacientes na pós-menopausa, das quais 30 eram continentes e 27 apresentavam incontinência urinária de esforço. Foram subdivididas, conforme o tempo de pós-menopausa, em até 5 anos ou com mais de 5 anos.

Todas submeteram-se à anamnese, exames físico geral e ginecológico, dosagens hormonais (LH e FSH), urina I e urocultura, diário miccional, teste do cotonete, ultrasonografia pélvica e do colo vesical por via subclitoriana e estudo urodinâmico.

A comparação entre os grupos de mulheres continentes e incontinentes, que apresentavam exame físico semelhante, conforme o tempo de pós-menopausa (até 5 anos e com mais de 5 anos), não revelou alterações significativas em relação ao diário miccional, ao teste do cotonete, à posição e mobilidade do colo vesical ao ultrasom e ao estudo urodinâmico. Em especial, os nossos resultados não demonstraram haver relação entre o tempo de pós-menopausa e alteração da pressão de fechamento uretral comparando-se esses dois grupos de mulheres continentes e os dois grupos de mulheres incontinentes.

Observamos resultados significantes quando se comparou o grupo de mulheres continentes e incontinentes. A análise do diário miccional revelou aumento no número de micções diurnas nos dois subgrupos de pacientes incontinentes em comparação às continentes.

Quanto ao teste do cotonete houve aumento significante no ângulo de variação da posição do colo vesical com a bexiga cheia nas mulheres incontinentes com até 5 anos de menopausa comparativamente às continentes.

No que tange à topografia do colo vesical ao ultrasom, as pacientes incontinentes com até 5 anos de menopausa apresentaram significante aumento na variação de sua posição (mobilidade) ao esforço em relação às continentes.

O estudo urodinâmico mostrou diminuição da capacidade vesical do primeiro desejo miccional e do volume urinário à fluxometria nas pacientes incontinentes com até 5 anos de pós-menopausa, em comparação às continentes. Observamos, também, diminuição na pressão máxima de fechamento uretral com a bexiga cheia e vazia nas pacientes incontinentes com mais de 5 anos de pós-menopausa, em relação às continentes.

Palavras-Chave: Ultra-Som, Incontinência Urinária, Menopausa.

\section{ERRATA}

Rev Bras Ginec Obstet 1997, 18(5):363

Trabalho: Associação entre diversos tipos de DNA-HPV e outras infecções

vaginais com lesões intra-epiteliais cervicais de alto grau.

Autores: Roteli-Martins CM, Derchain SFM, Das Dôres G.B,

Siqueira SAC, Alves VAF, Panetta K.

Serviço: Departamento de Tocoginecologia da Faculdade de Ciências Médicas - UNICAMP;

Digene Inc., Brasil; Hospital Maternidade "Leonor Mendes de Barros";

Laboratório de Anatomia Patológica do Hospital Ipiranga e Departamento de

Anatomia Patológica da Faculdade de Ciências Médicas - FMUSP.

Apoio Financeiro: FAPESP (processo $n^{\circ}$ 96/1730-5). 